\title{
Experimental investigation of thermal performance in a rectangular channel using compound structure
}

\author{
P. S. Patil 1 , K.K. Dhande 2 \\ 1 Department of Mechanical Engineering, Rajarshi Shahu College of Engineering, Pune, 411033, India \\ Phone: +91-9049300947 \\ 2 Department of Mechanical Engineering, D.Y. Patil Institute of Technology, Pune, 411018, India
}

\begin{abstract}
An experimental study was conducted to measure the heat transfer and pressure drop in a rectangular channel emphasizing a compound structure to improve the cooling performance of gas turbine blades. W shaped, semicircular, and multi semicircular shaped ribs with dimples are studied and applied to a lower surface of a channel. The experiment was carried out at a Reynolds number ranging from 10,000 to 32,000 and the ratio of pitch $(P)$ to height $(e)$ of the rib was 10 . Also, the ratio of rib height $(e)$ to channel hydraulic diameter $\left(D_{h}\right)$ was 0.187 and the dimple depth $(\delta)$ to dimple diameter $(D)$ ratio was 0.2 . It was observed that the combination of ribs and dimple channel (compound channel) has an average of $23 \%$ more heat transfer than the ribbed channel. W rib compound channel shows the highest thermal performance and enhanced up to $30 \%$ more heat transfer than semi and multi-semicircular compound channel. friction rise was observed in the compound channel compared to the ribbed channel.
\end{abstract}

\author{
ARTICLE HISTORY \\ Received: $19^{\text {th }}$ May 2020 \\ Revised: $28^{\text {th }}$ Jan 2021 \\ Accepted: $30^{\text {th }}$ Mar 2021

\section{KEYWORDS} \\ Reynolds number; \\ Nusselt number; \\ compound structure; \\ heat transfer coefficient; \\ Nusselt number ratio.
}

\section{INTRODUCTION}

Heat transfer enhancement concept was observed in various applications such as in gas turbine blades, air heaters of the solar system, heat exchanger and cooling of electronic instruments. To get more output and efficiency it is necessary to operate gas turbines at very high inlet temperatures. These temperatures are intensely greater than the melting temperature of blade material, hence turbine blade needs cooling to prolong its life expectancy and for a safe operation. Internal and external cooling methods are used to cool the gas turbine blade and among the methods of internal cooling are jet impingement, rib turbulating, pin-fin, protrusions and dimples [1]. Rib turbulators are frequently used to cool gas turbine blades, but this is susceptible to great pressure loss. Thermal performance of rib turbulators depends on various geometrical parameters and conditions of flow, such as rib shape, aspect ratio, shape of the channel, rib pitch to height ratio (p/e), blockage ratio of the channel, rib attack angle $(\alpha)$ and the rib arrangement itself (inline or staggered). Although many of these rib geometries have been studied earlier, Lee experimentally investigated the parallel angled ribs in divergent channel and stated that $90^{\circ}$ ribs performed well compared to $30^{\circ}, 45^{\circ}$ and $60^{\circ}$ angled ribs [2]. In addition, $\mathrm{V}$ shaped rib performed better compared to $90^{\circ}$ and angled ribs [3,4]. Moreover, Kumar and Amano [5] reported on continuous $\mathrm{V}$ and broken $\mathrm{V}$ - ribs and showed that broken ribs can outperform continuous ribs.

Rallabandi [6] studied the effect of $45^{\circ}$ angled round edge ribs and concluded that at greater rib height of $45^{\circ}$, round edged rib shows similar performance as sharp edged rib. Furthermore, sixteen rib shapes were numerically presented and it was concluded that the performance of boot-shaped rib was the highest among the tested ribs [7]. Hagari [8] focused on small W shaped rib at Reynolds number from 40,000 to 5,50,000. Their results indicated that enhancement in heat transfer observed were within 2.6 to 3.2 and friction factor 3.2 to 4.5 times better than for the smooth channel [8]. Additionally, the maximum improvement in heat transfer was found in $\mathrm{W}$ shaped rib when aspect ratio was doubled, such as for $\mathrm{W}$ rib $\mathrm{AR}=2: 1,2 \mathrm{~W}$ rib $\mathrm{AR}=4: 1$ and $4 \mathrm{~W}$ rib $\mathrm{AR}=8: 1[9]$.

In recent years, due to the advancement in technology, new ribs were developed and presented by researchers. Singh [10] investigated numerically criss cross rib pattern formed by $45^{\circ}$ angled rib turbulators for inline and staggered arrangements. They found an improvement in heat transfer from 2.7 to 3.1 and also saw identical performance for both inline and staggered arrangements. Included too were wavy ribs presented at Reynolds number from 10,000 to 40,000 and the conclusion is that the height, radius and angle of rib has big influence on heat transfer enhancement. Ribs with more height and massive round radius demonstrated superior performance compared to other configurations [11]. Xie reported crescent ribs in straight, concave and convex forms at Reynolds number ranging from 8000 to 24000 , concluding that concave rib performed better with $21-41 \%$ increase in heat transfer compared to straight ribs and 15-80\% more pressure loss [12]. Dimples are used in cooling passages due to its advantage in low-pressure penalty, while the heat transfer enhancement is lesser than that expected in ribbed channels. Rao [13] experimentally studied the influence of dimple depth on thermal performance at Reynolds number from 8200 to 80800 . Their result indicated that pin fin-dimple channel with dimple depth to print diameter ratio ( $\delta / \mathrm{D}) 0.1-0.2$ has relatively lower friction than dimple depth ratio $(\delta / \mathrm{D})$ 0.3. Also presented were different dimple shapes and conclusion that the shape of dimple does have effects on the thermal 
performance of the channel. Teardrop dimples had 18\% more heat transfer compared to spherical dimples [14]. Ribs and dimples alone have both advantages and disadvantages relating to the augmentation of heat transfer.

Few researchers focused on combination of two different shapes of ribs, investigated three geometries (semicircular, rectangular and hybrid) at aspect ratio of channel 1:4 and Reynolds number ranging from 12500 to 86500 showed that hybrid ribs performed better than other tested ribs [15]. Again, presented combination of semicircular and triangular (hybrid) ribs at Reynolds number of 12,640. The rib pitch ratio (p/e) was from 6.6 to 53.3 and showed that performance of hybrid ribs was maximum at p/e of 13.3 [16]. Recently few researchers focused on combining two techniques, such as ribs with dimples, ribs with protrusions, pin fin with dimples and dimples with protrusions. Kaur and Singh [17] presented $\mathrm{V}$-shaped protrusion/concavity with miniature V-rib and concluded that the combination of V-rib and V-protrusion configuration showed the highest thermal hydraulic performance (THP) of 2.15. Also, Singh carried out experiments for combination of ribs and dimples, ribs such as $45^{\circ}$ angled, $\mathrm{W}$ and $\mathrm{M}$ shapes were studied along with dimples at Reynolds number 19500 to 69000 . Result indicated that the compound channel of rib and dimple offered more thermal-hydraulic performance over channel with ribs alone or dimples alone [18]. Dimples and protrusions presented for plate heat sink obtained maximum performance at a staggered arrangement with dimple pitch ratio (s/d) 2.5 and dimple depth ratio 0.5 [19]. Also numerically presenting the effect of combining dimple and secondary protrusions on heat transfer indicates that dimple channel with secondary protrusions showed higher thermal performance than regular dimple channel [20]. Zheng, who numerically studied different groove-protrusions effect on heat transfer and flow characteristics, also studied combination of groove-protrusions-rib impact on heat transfer [21].

From literature, it is seen that there is still further scope to work on heat transfer techniques for gas turbine blade. Previous researchers mainly focused on the ribs or dimples alone and hybrid ribs, only few focused on combining the two techniques for cooling applications. The objective of the present study is to determine new cooling method for gas turbine blade, which is essentially the combination of two separate augmentation techniques. This research work mainly focused on combination of W shape, semicircular and multi semicircular shape ribs with spherical dimples for cooling method.

\section{EXPERIMENTATION}

\section{Detail of Experimental Set Up and Procedure}

Experimental set-up used for expermentation is shown in Figure 1 with the main components are centrifugal blower, an orifice flow meter (orifice plate assembly), rectangular channel with test section assembly, data acquisition system, digital multichannel temperature indicator, dimmer-stat and $\mathrm{k}$ type thermocouples. The rectangular channel used was made from Bakelite sheet $12 \mathrm{~mm}$ thick and aspect ratio of the channel was 4:1. The hydraulic diameter and length of rectangular channel was 32 and $560 \mathrm{~mm}$, respectively. A centrifugal blower was selected based on the pressure loss calculations and the air flow rate was controlled through dimmer-stat. In the experiment set up, a blower was followed by a flow straightener to straighten the flow after the entrance section of length $10 \mathrm{Dh}$ was connected to the rectangular channel to regulate the flow. At the other end, to reduce the end effects of flow exit, section length 6 Dh was attached to the rectangular channel.

An orifice plate with $U$ tube manometer was attached to measure the air flow rate and the pressure drop across the channel was measured with the help of manometer connected at the inlet and outlet of the duct. Also, K type thermocouples were used to measure the temperature at various points in test section and connected to either a digital twelve channel temperature indicator or to digital data logger with sampling rate at $25 \mathrm{~Hz}$. Two thermocouples were placed to measure the air inlet and outlet temperatures, and ten thermocouples were provided to measure the surface temperature of test plate. Uniform heat flux was supplied by the mica flat plate (rectangular) heater $480 \mathrm{x} 50 \mathrm{~mm}$ in surface area and heat input was varied with the help of dimmer- stat. All the data were recorded under steady state condition, initially taking $2-2.5$ hours to attain the steady state condition.

\section{Experimental Test Section}

For the experimental test section, a $10 \mathrm{~mm}$ aluminium sheet was used and the width of test plate was selected as per aspect ratio $(A R=4: 1)$ of the channel. The ribs are pasted onto the test plate surface using thermal glue and dimple was formed on the test plate surface with the help of a special ball nose tool and vertical milling machine. The ball nose tool was designed by considering dimple print diameter and dimple depth. Uniform heat flux was supplied by a mica flat plate heater, placed between the test plate and the support plate. To prevent heat loss, $5 \mathrm{~mm}$ glass wool insulation was placed between the heater and the support plate. The assembly of test plate, heater and the supporting plate was clasped with bolts and inserted in a rectangular channel. 


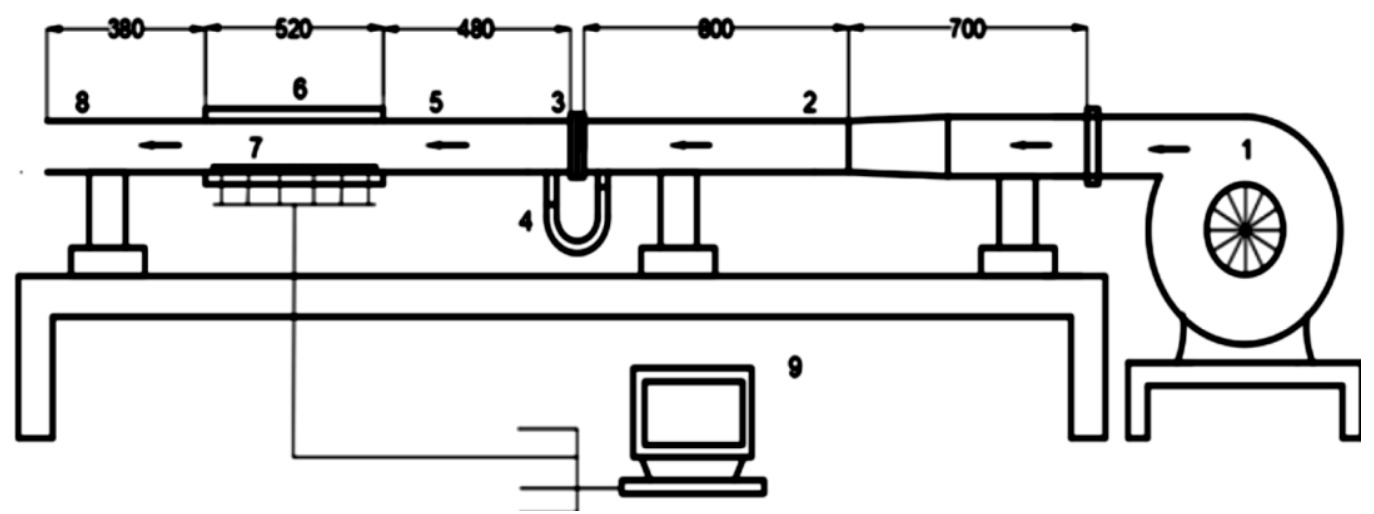

Figure 1. Experimental setup

1- blower, 2-developing section, 3- orifice plate, 4- U tube manometer, 5-inlet section, 6- rectangular channel, 7- test section, 8 - exit section, 9- data logger

\section{Rib Configurations}

The $\mathrm{W}$ shaped rib was manufactured from a $5 \mathrm{~mm}$ aluminium square bar. The angle between $\mathrm{W}$ shape was $52^{0}$ with the side length rib of $42 \mathrm{~mm}$. Four sides of the rib are pasted to form $\mathrm{W}$-shaped rib. Semi-circular and multi semi-circular shaped ribs are manufactured from $80 \mathrm{~mm}$ and $40 \mathrm{~mm}$ diameter aluminum pipe. Aluminium bar was first hollowed by using a boring tool and then ground to size on a grinding machine. Height and width of rib was $5 \mathrm{~mm}$, blockage ratio (e/Dh) of the channel was 0.187 and the rib pitch to height ratio (P/e) was kept at 10 for all cases. For dimples, special ball nose tool was designed and embossing on the surface of the test plate was done using a special purpose machine. Dimple print diameter was $20 \mathrm{~mm}$ and dimple depth to dimple print diameter ratio $(\delta / \mathrm{D})$ was kept at 0.2 . Figure 2 shows the top view of different ribs and their compound arrangements.

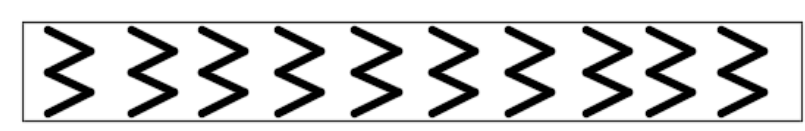

(a) W-Shape ribs

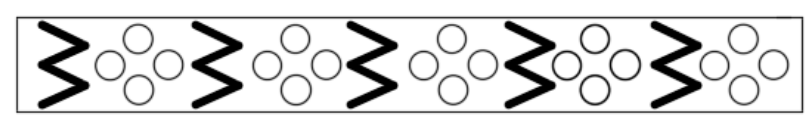

(c) W ribs - dimple compound channel

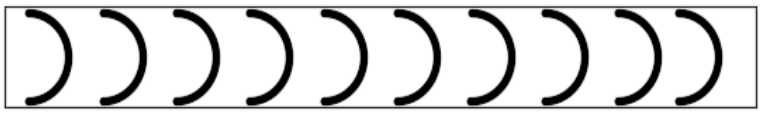

(b) Semi-circular shape ribs

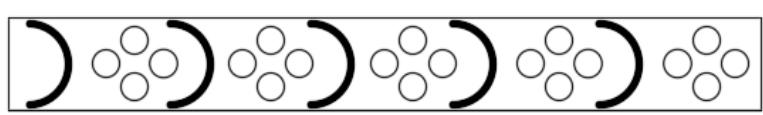

(d) Semicircular ribs - dimple compound channel

Figure 2. Different ribs and compound arrangements

Rib arrangement - Various cases of ribs and compound structures were studied at Reynolds number ranging from 10000 to 32000 . First up was plain plate, then dimple plate, followed by W shaped, semicircular and mult semicircular shaped ribs ending with $\mathrm{W}$ shaped rib + dimple, semicircular rib + dimple and multi semicircular rib + dimple were tested. In compound structure, after every rib, 4 spherical shaped dimples are used and the horzontal and vertical pitch between dimples are kept different. Figure 3 shows actual photographs of the rectangular duct and test plates.

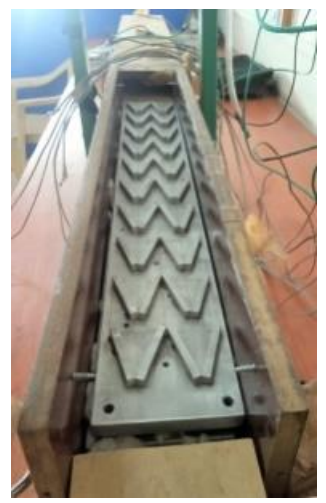

(a) $\mathrm{W}$ shape rib in duct

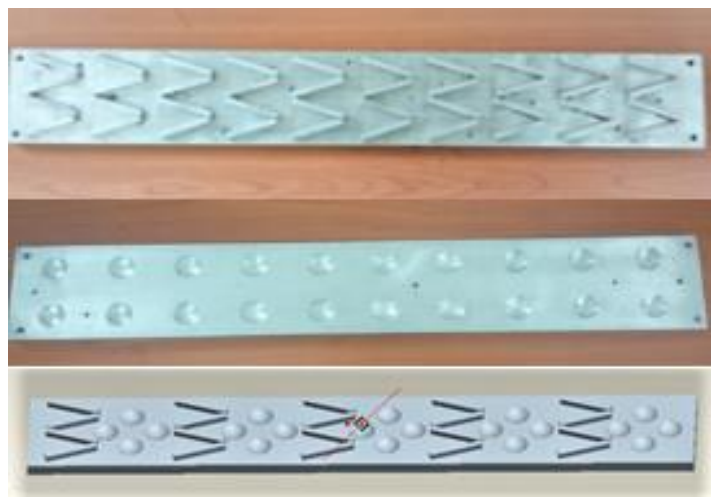

(b) W shape rib, dimple and compound plate

Figure 3. Actual photographs of rib configurations 


\section{DATA REDUCTION}

Nusselt number - At steady-state conditions, surface temperatures of test plate, air temperatures, and pressure drop along test sections are recorded. From this data, various parameters such as Reynolds number, heat transfer coefficient, Nussult number and friction factor were calculated. Reynolds number was calculated using Eq. (1) suggested by Rallabandi [6], where $g=$ density of air, $v=$ velocity of air, $\mu=$ dynamic viscosity $(\mathrm{kg} / \mathrm{m}-\mathrm{s}), \mathrm{D}_{\mathrm{h}}=$ hydraulic dia. of the channel, also heat transfer coefficient (ha) was calculated using Eq. (2) given by Kumar and Amano [5] where A= surface area of test plate, $\mathrm{Ts}=$ average surface temperature of test plate, $\mathrm{Tb}=$ bulk temperature of the air.

$$
\begin{aligned}
& \text { Reynolds number }(R e)=\frac{\rho v D}{\mu} \\
& h a=\frac{Q_{n e t}}{A\left(T_{s}-T_{b}\right)}
\end{aligned}
$$

Net heat input $\left(\mathrm{Q}_{\text {net }}\right)$ was calculated from total heat input supplied minus heat loss from the test section (conduction and convection loss), the losses found were almost about 10-12 \% of the overall heat flux supplied. To prevent heat loss, the channel was made from a bakelite sheet. The Nusselt number was calculated using Eq. (3) proposed by Kaewchoothong [4] where $\mathrm{k}=$ thermal conductivity of air and Nusselt number ratio was calculated using Eq. (4).

$$
\begin{gathered}
N u=\frac{h_{a} D_{h}}{k} \\
\frac{N u}{N u_{o}}=\frac{h D_{h} / k}{0.023 \operatorname{Re}^{0.8} \operatorname{Pr}^{0.4}}
\end{gathered}
$$

Frictional Losses - frictional losses were calculated by considering the pressure drop along the channel and Eq. (5) was used to calculate the friction factor as suggested by Rao [13]. The frictional factor ratio calculation uses Eq. (6) as suggested by [4].

$$
\Delta P=\frac{\mathrm{fL} \rho V_{a v g}^{2}}{2 \mathrm{D}}
$$

where, $f=\left(P_{i}-P e\right) /\left[\left(4\left(L / D_{h}\right)\left(1 / 2 \rho V^{2}\right)\right]\right.$

$$
\frac{f}{f_{0}}=\frac{\mathrm{f}}{0.079 \mathrm{Re}^{-1 / 4}}
$$

Thermal Performance - considering the Nusselt number and friction factor ratio, thermal performance of every configuration was calculated using Eq. (7) as suggested by Rallabandi [6], where Nuo = plain plate nusselt number, $\mathrm{f}_{0}=$ plain plate friction factor.

$$
\text { Thermal Performance }=\frac{\left(N u / N u_{0}\right)}{\left(f / f_{0}\right)^{1 / 3}}
$$

\section{Error Analysis}

The experimental uncertainty was estimated using the method developed by Kline and McClintock [22].The maximum error in temperature measurement, flow rate \& pressure drop were observed $0.6{ }^{0} \mathrm{C}, \pm 2.7 \%$ and $\pm 2.4 \%$ respectively.The maximum experimental uncertainty in the Nusselt number was estimated at $8.8 \%$ and errors were observed in Nusselt no. due to bias and precision errors in thermocouples measurements. The uncertainty in the friction factor was estimated to be $7.5 \%$ and friction factor error was observed due to precision errors that occurred in the measurement of static pressures.

\section{RESULTS AND DISCUSSION}

\section{Validation of Smooth Duct}

The value of the Nusselt number and friction factor for a plain plate were calculated from collected experimental data. The value of the experimental Nusselt number for plain plate (smooth duct) was then compared against the value obtained from the Dittus-Boelter correlation shown in Eq. (8). Also, the friction factor value of the experimented plain plate was checked against the values calculated from the modified Blasius correlation shown in Eq. (9).

$$
N_{u}=0.023 \operatorname{Re}^{0.8} P_{r}^{0.4}
$$




$$
f=0.079 \mathrm{Re}^{-1 / 4}
$$

The values obtained from experimental data and correlation equations of Nusselt number are then presented as a function of Reynolds number in Figures 4 and 5, respectively. It is observed that the average error in the Nusselt number was $\pm 9 \%$ while friction factor was $7.1 \%$. Thus, good agreement between experimental and estimated values is observed. Also, these two equations validate the smooth (plain) duct results.

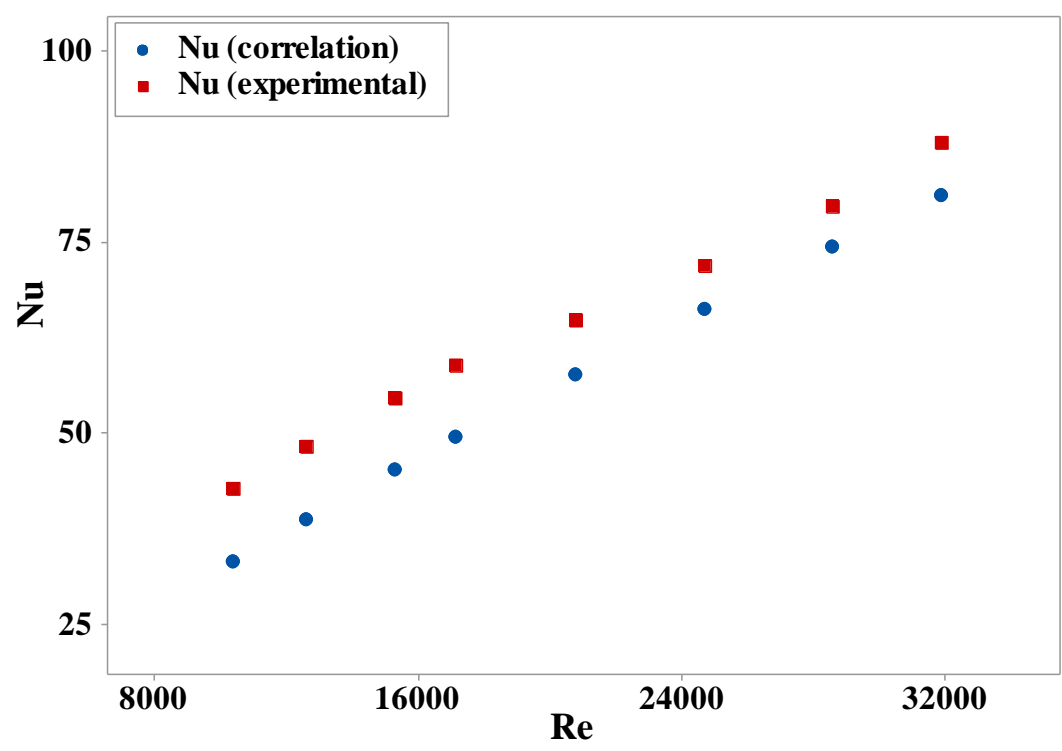

Figure 4. Deviation in experimental and correlation value of plain plate

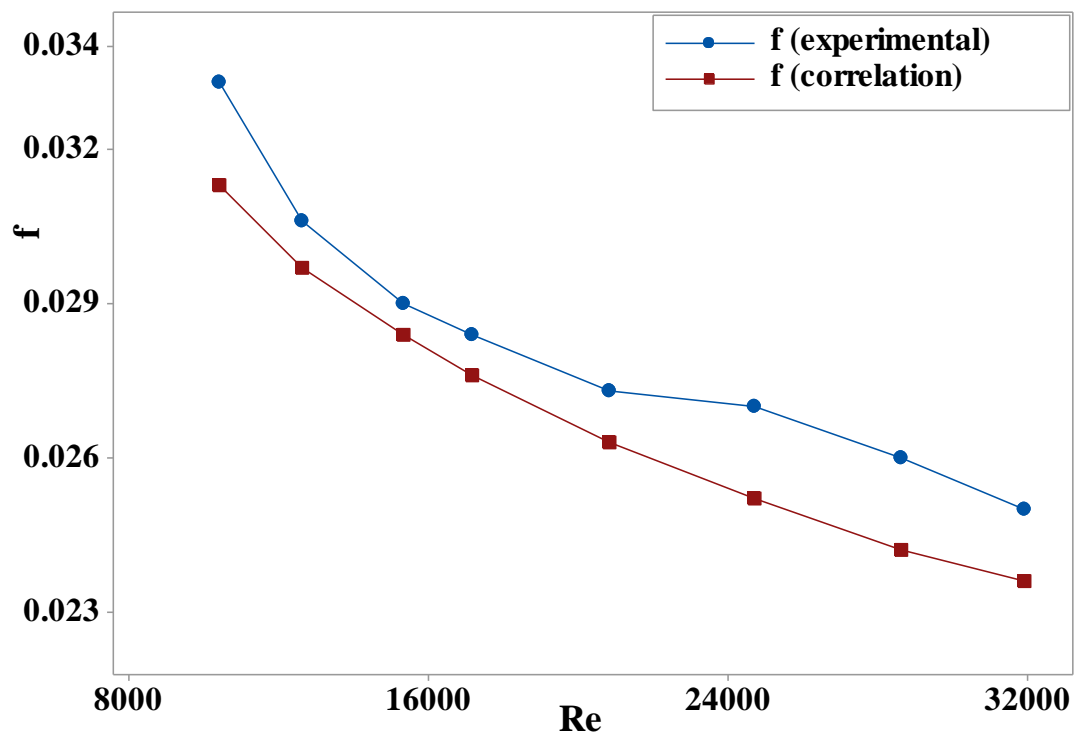

Figure 5. Deviation in experimental and correlation value of friction factor (plain plate)

\section{Rib-Dimple Duct}

First heat transfer coefficient, Nussult number, and friction factor are presented and discussed for all configurations tested at a Reynolds number ranging from 10000 to 32000. The Nusselt number and friction factor results of the compound channel were then compared with the ribbed channel and smooth duct under the same experimental conditions.

\section{Heat transfer coefficient}

The convection heat transfer coefficients of the rib and compound structure are shown in Figure 6. The convection heat transfer coefficient increased as the Reynolds number increased. The W and the semicircular compound channels have more heat transfer coefficient than ribbed channel but the multi semicircular compound channel has less heat transfer than semicircular rib. Semicircular rib channel has greater heat transfer coefficient. 


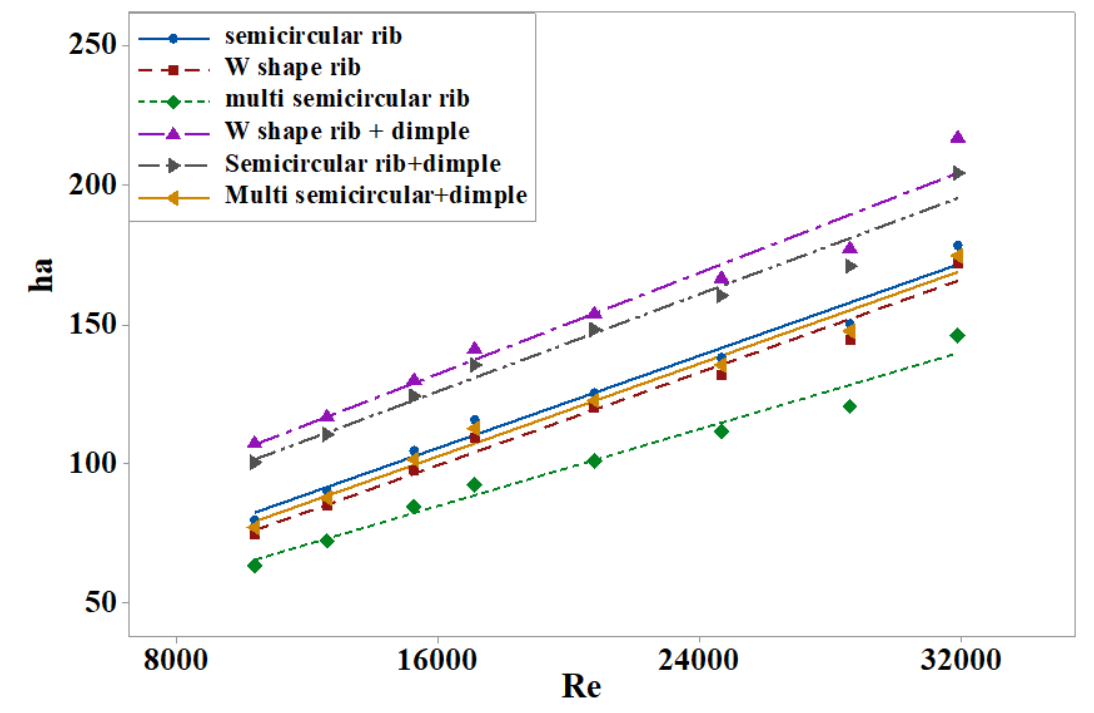

Figure 6. Variation of heat transfer coefficient (rib and compound channel)

\section{Nusselt Number}

The Nusselt number for the compound channel was calculated from experimental data and presented in Figure 7 . It shows that the compound channel performed better than the plain duct and dimple channels. The compound channel has 160 and $130 \%$ more heat transfer over plain and dimple channels, respectively. The $\mathrm{W}$ shaped compound channel performed better compared to other tested compound channels. In the present compound channel, W shaped rib was made by joining two $\mathrm{V}$ ribs and creating a larger heat transfer region near the $\mathrm{V}$ angle. Also, being a compound channel every rib follows four dimples, such as in the enlargement area of $\mathrm{V}$ shape and at the tip of $\mathrm{V}$ shape where three dimples and one dimple respectively, are present. Because of this position, flow separation and reattachment of shear layer forms across the top of the dimple and mixing of primary and secondary vortices are seen due to more heat transfer observed in W shaped compound channel. In the case of the semicircular rib-dimple compound channel, the rib has a magnified high heat transfer region because of the curvature. Also, four spherical dimples followed by an enlarged area of each rib due to turbulence created by ribs are then mixed with flow separation layer of dimples, hence less fluid ejection were seen from the center part of the dimple. Because of these reasons, heat transfer had increased. The W compound channel enhanced more heat transfer over the semicircular compound channel, but less difference was found. In multi semicircular ribbed compound channel, less effect of the rib was found, and less impact of dimple for heat transfer so finally, less enhancement was observed compared to other compound channels. Dimple configuration has the least heat transfer enhancement compared to all tested configurations but it is more than the plain duct.

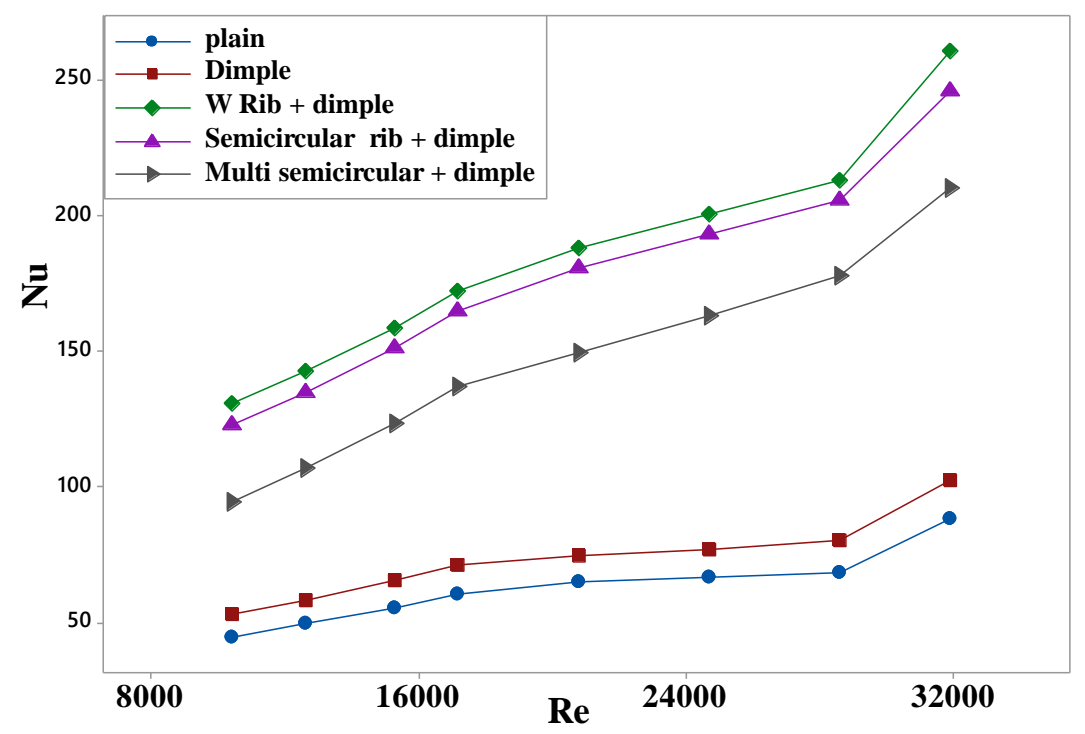

Figure 7. Variation of Nusselt number against Reynolds number (compound channel)

Figure 8 shows the deviation of Nusselt number related to Reynolds number for rib alone and compound channels. It shows Nusselt number was increased as Reynolds number increased, also Nusselt number was the highest for compound channel related to the rib alone channel; similar trend of results was observed by [17]. It means the compound channel 
has more enhancement in heat transfer than a rib-alone channel. Heat transfer in compound channel enhancement was observed because of two reasons, one for introducing rib in a dimpled channel and another for filling rib pitches with dimples in the rib turbulated channel. The $\mathrm{W}$ rib compound channel had the best performance compared to the rib alone and other tested compound channels.

In the case of rib channels, semicircular ribs performed better compared to tested ribs [12]. The semicircular rib offered a large frontal area due to its curved shape as that shape creates reduced low heat transfer region behind ribs and enlarged high heat transfer region in front of ribs, hence heat transfer has increased. The multi semicircular rib has a low heat transfer coefficient compared to other ribs and compound channels. The multi semicircular rib was made from a combination of two small semicircular ribs; due to this single wall created between curvature shapes offers a less enlarged region in front of ribs.

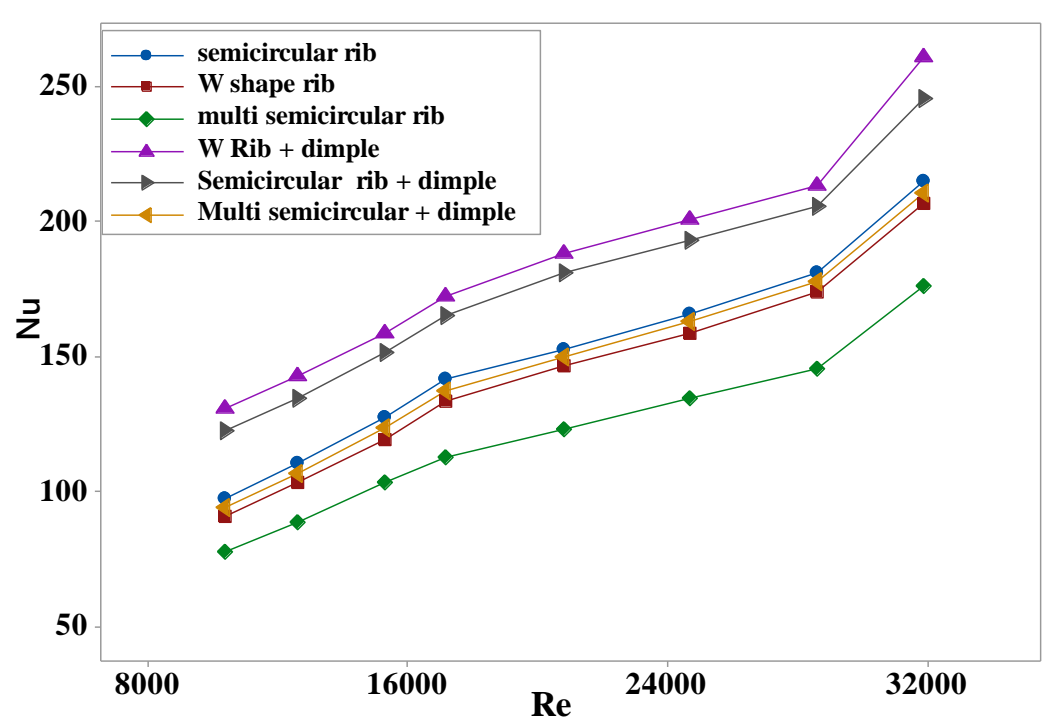

Figure 8. Nusselt number against Reynolds number for all configurations

Figure 9 shows the relation of Nusselt number ratio (Nu/Nuo) to Reynolds number. Initially Nusselt number ratio shows decreasing trend but after Reynold, number 28600 shows an increasing trend. The Nusselt number ratio was varied from 2.12 to 3.11 for the compound channel and 1.74 to 2.62 for the ribbed channel. The compound channel has a more Nussult number ratio over that of the ribbed channel because it takes advantage of both geometries such as rib as well as dimple. Ribs have high heat transfer associated with high-pressure penalty whereas dimples have less pressure drop but moderate heat transfer enhancement, due to this reason compound channel performed better than the ribbed channel. In the case of a compound channel, the Nusselt number ratio was highest for W shaped rib-dimple compound channel and the least for a multi-semicircular rib-dimple compound channel.

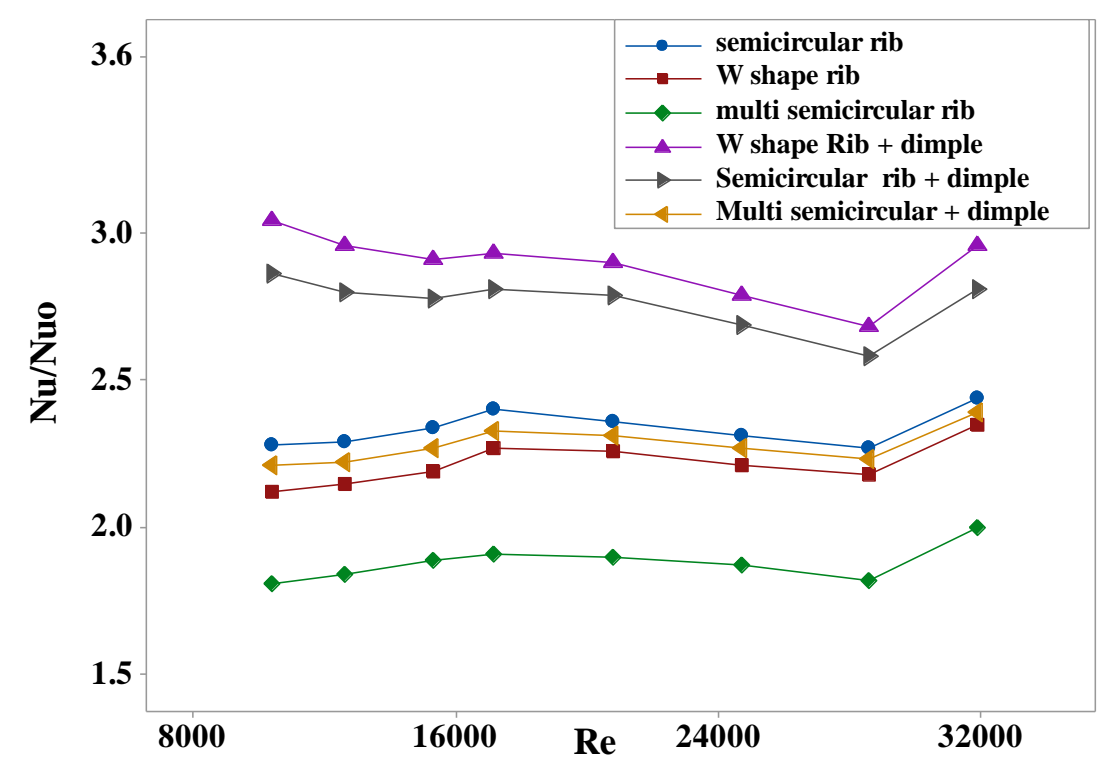

Figure 9. Nusselt number ratio versus Reynolds number (all configurations) 
In the case of rib channel Nusselt number ratio was highest for semicircular rib, after that W shaped and multi semicircular ribs. Rib channel enhanced heat transfer due to attachment and reattachment of boundary layer and also turbulence in the flow [6]. W shape rib means a combination of two $\mathrm{V}$ ribs, as $\mathrm{V}$ rib performance was better than inclined ribs; hence $\mathrm{W}$ rib enhancement was more but less compared to the semicircular rib.

One noteworthy point here is that in the case of compound channel, W shaped rib-dimple compound channel shows more heat transfer but in ribbed channel, semicircular rib performed better. It means that role of dimple and rib shape varied the performance, as by using ribs heat transfer is improved but at the same time pressure drop increased; to get more performance requires a combination of two cooling techniques such as rib - protrusion, rib - dimple, protrusiondimple, etc. If only number of ribs is increased heat transfer will improve but pressure drop will also increase by more percentage meaning that performance will remain the same. From the experimental result of dimples, it is understood that dimple channel shows less friction compared to ribbed channel if some ribs are replaced with dimples and influencing the performance. This technique was applied in the present study and it was decided to place four dimples after every rib; amounting to the total of five ribs and 20 dimples used in place of ten ribs. Dimples are placed in this way; two dimples were kept horizontal in position and two dimples kept in vertical position, with vertical dimples are angled at 40 deg. angle to horizontal and kept at a different pitch of horizontal and vertical.

\section{Frictional Losses}

This section discusses the friction factor for rib and compound channel, where friction factor is required for finding the thermal-hydraulic performance of duct and pumping power. Figure 10 presents the friction factor for a compound channel, observed average of 280 and $150 \%$ more friction in the compound channel than plain and dimple channel respectively. More friction was observed in the compound channel by reason ribs and dimples created retardation as well as a disturbance in the flow. The semicircular rib-dimple compound channel shows the highest friction and the dimple channel shows less friction than the compound channel.

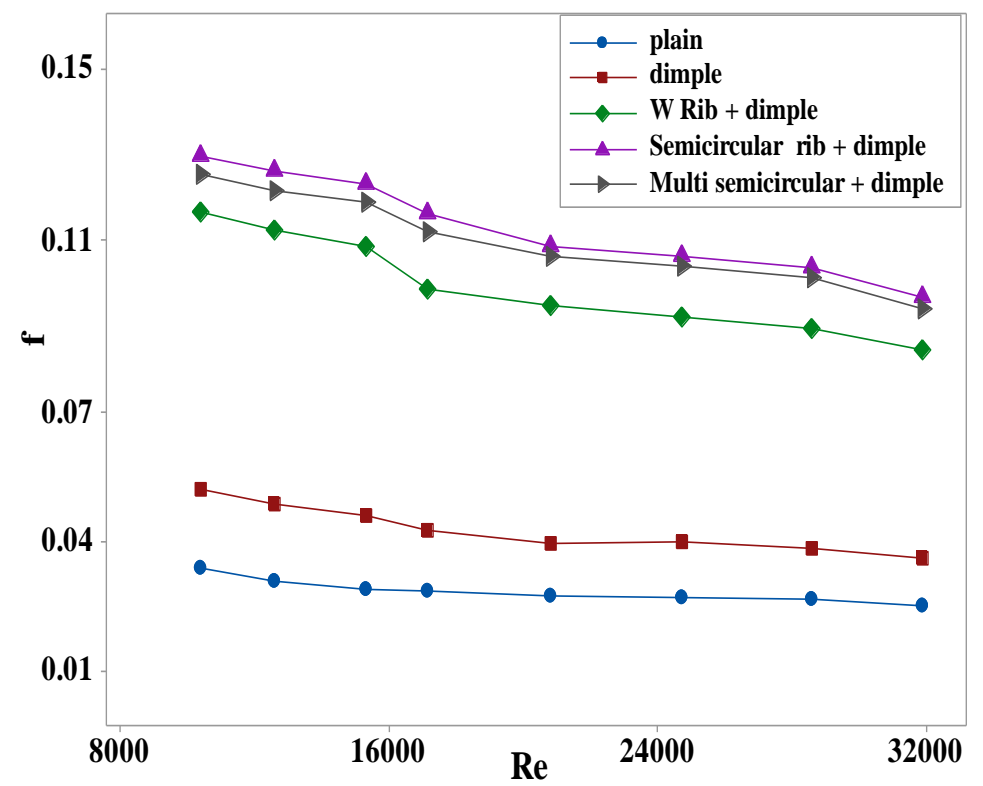

Figure 10. Friction factor variation with Reynolds number for compound channel

The results of friction factor for the rib and compound channel are shown in Figure 11. For each configuration (geometry) friction factor shows a gradually decreasing trend as the Reynolds number increased [19]. This is because of viscous sublayer suppression, as increased Reynolds number requires decreased boundary layer thickness to cause an increase in fluid velocities in the boundary layer, and also retardation to flow is reduced as velocity increased. Fig. 11 also indicates friction factor for the compound channel was somewhat greater than the friction factor for ribbed channel. In the ribbed channel, only ribs disturbance was high as friction was observed increased but in the case of the compound channel every rib follows the dimple as dimples friction was reduced. But hereafter, friction of a rib with no dimples compared against friction of a single rib with four dimples will see more friction from the four dimples; because of this reason, more friction in compound channel can be observed compared to the ribbed channel.

The compound channel has an average of $25 \%$ more friction compared to the ribbed channel. The semicircular rib compound channel shows the highest friction followed by multi semicircular and $\mathrm{W}$ rib compound channels. In semicircular rib compound channel, the front area of rib followed by four dimples which generate more turbulence, due to the impact of both ribs and dimples observed have more friction compared to other compound channels. The difference between semicircular and multi semicircular compound channel friction was less because of similarity in shape with the only difference being the radius of the rib. In W shaped rib - dimple compound channel shows less friction compared to 
other tested configurations because the thickness of boundary layer between ribs is more than other ribs, therefore less friction offered by ribs hence, less friction was found.

In the ribbed channel, semicircular rib shows the highest friction and observed $205 \%$ more friction compared to a plain plate. The semicircular rib has more area and due to that it creates more pressure drop. A multi semicircular rib was made from a combination of two small semicircular ribs, hence slightly reduced area so it has slightly less friction than semicircular rib. In the case of W shaped rib, friction observed was due to the high turbulence created by the sharp edges of the ribs, W shaped rib has less area and from that it creates less pressure drop compared to semicircular and multi semicircular ribs.

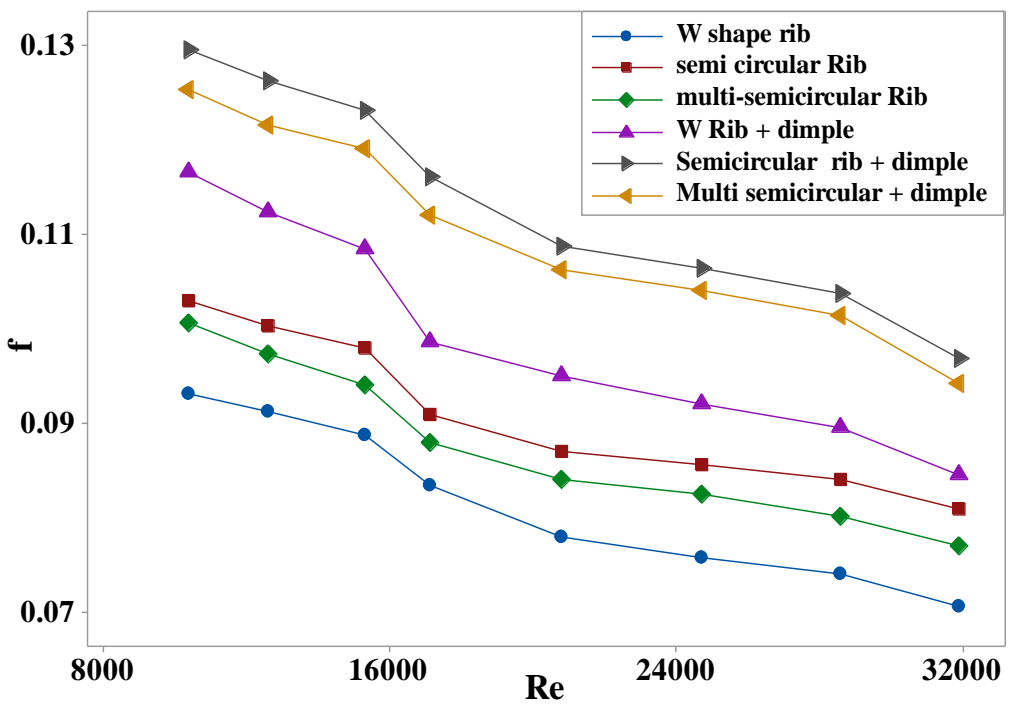

Figure 11. Friction factor variation with Reynolds number (all configurations)

\section{Thermal Performance (TP)}

Thermal performance was calculated by considering heat transfer enhancement and frictional losses. Figure 12 shows the thermal performance for the rib and compound channel, denoting a slowly decreasing and increasing trend but after Reynolds number 28600, an increasing trend is observed for all configurations. The compound channel shows the highest thermal performance than the rib alone channel.

The $\mathrm{W}$ compound channel offered the maximum thermal performance compared to all tested configurations. It shows more heat transfer improvement and decreased frictional losses over the complete configuration tested. Semicircular ribdimple compound channel performed better over other configurations but less compared to $\mathrm{W}$ shaped rib-dimple configuration.

In the case of rib channel, semicircular rib shows better performance compared to tested ribs and multi semicircular rib shows the lowest thermal performance compared to all tested configurations. Here, one observation noticed that in the case of compound channel $\mathrm{W}$ gave the best compound channel performance but in the case of rib channel, semicircular rib performance was the best. Also, the $\mathrm{W}$ rib has less friction compared to semicircular rib and multi semicircular rib.

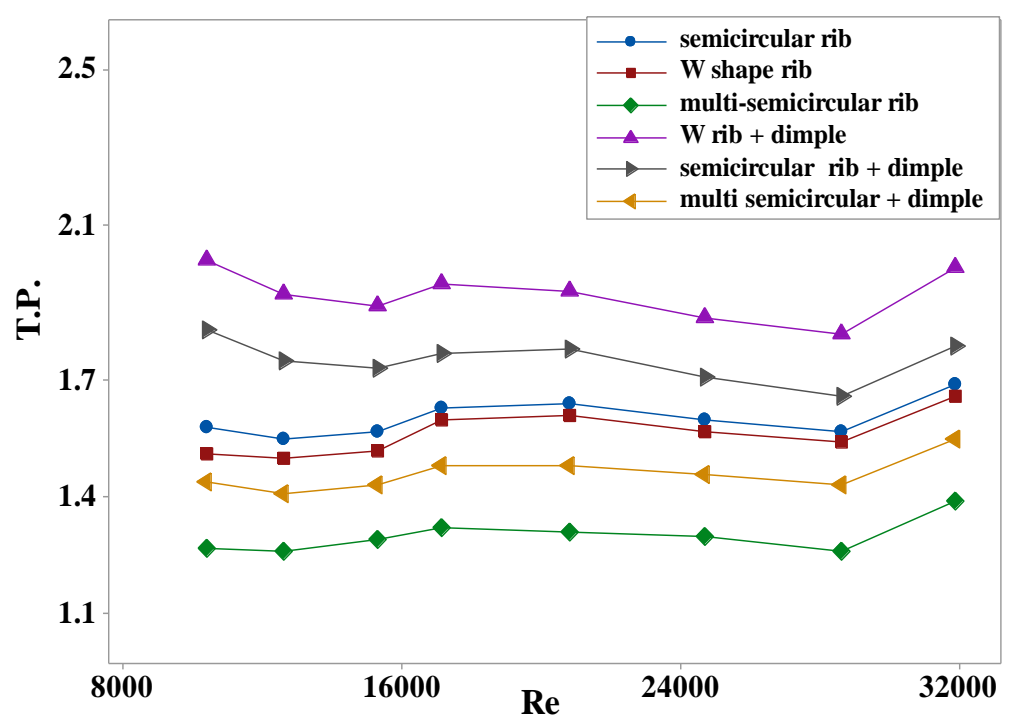

Figure 12. Thermal hydraulic performance (THP) 


\section{Comparsion of Results with Previous work}

As discussed, plain duct results are validated using correlation and found good agreement between experimental and correlation results similar to experimental results of ribs and compound channel when compared with previous work. Present results of the semicircular rib are then compared with the previous work of Alfarawi [15], despite they worked on different rib pitch to height ratios (p/e), the results are as shown in Figure 13(a). From the figure, it is observed that Nusselt number of the smooth duct and semicircular ribs increased as Reynolds number increased; the same trend of results are found in present experimental results of the semicircular rib as shown in Figure 13(b).

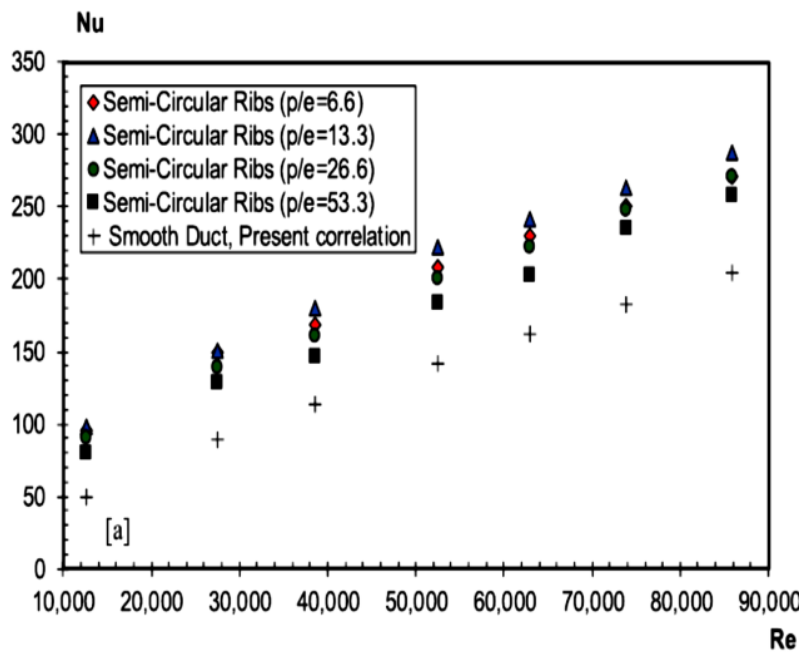

Figure 13(a). Previous results of semicircular rib [15]

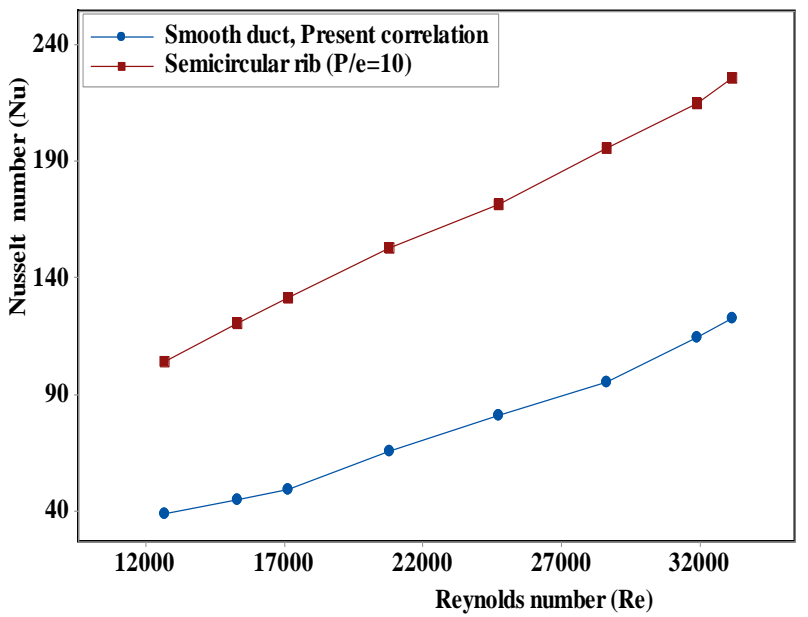

Figure 13(b). Present results of semicircular rib

Present experimental results of the compound channel are compared with previous work of Kaur and Singh [17], who worked on a combination of rib with protrusion enhancement method and shows 2.15 highest thermal-hydraulic performance than rib alone channel. In the present work, the rib-dimple compound structure shows 1.86 highest thermalhydraulic performance than the rib alone channel. Based on comparison of both results, it is concluded that the trend of improvement in the thermal performance is similar as shown in Figure (14). Present combination results of rib with dimple are again compared with previous work of Singh [18], as they worked on V rib with dimple combination. The comparison observed the same enhancement trend for compound structure.

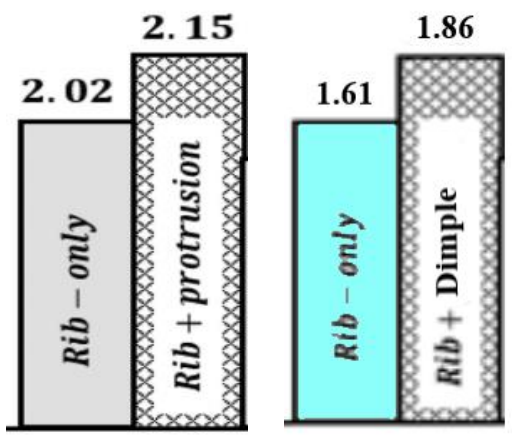

Figure 14. Comparsion of present results with previous work [17]

\section{CONCLUSIONS}

In the present research work, rib alone, dimple alone, and compound structure of rib-dimple are experimentally investigated. Semicircular, multi-semicircular and W shaped rib along with spherical dimples were studied to find out a new combination of rib-dimple for enhancing the cooling performance of gas turbine blades. The experimental results suggest the following conclusions:

- The compound channel shows better performance compared to plain, dimpled, and ribbed channels. Found average $165 \%$ more heat transfer and average $280 \%$ more friction compared to the plain duct.

- The compound channel shows an average of $23 \%$ more heat transfer compared to the ribbed channel and also found an average $25 \%$ more friction compared to the ribbed channel. The $\mathrm{W}$ shaped rib-dimple compound channel shows the highest thermal-hydraulic performance compared to the tested compound and rib channels.

- Semicircular rib performed better in the rib channel but in case of compound channel it shows less thermal performance than $\mathrm{W}$ shaped rib- dimple compound channel. 
- W shaped rib shows less friction than semicircular and multi semicircular rib.

- Multi semicircular compound structure and rib offered low performance in the present work.

\section{ACKNOWLEDGMENTS}

This research did not receive any specific grant from funding agencies in the public, commercial, or not-for-profit sectors.

\section{REFERENCES}

[1] J.C. Han, "Heat transfer and friction characteristics in rectangular channels with rib tabulators," J. Heat Transf., vol.110, pp. 321-328, 1988.

[2] M.S. Lee, S.S. Jeong, S.W.Ahn and J.C. Han, "Effects of angled ribs on turbulent heat transfer and friction factors in a rectangular divergent channel," Int. J. Therm. Sci., vol. 84, pp. 1-8, 2014.

[3] W. Peng, P.X. Jiang, Y.P.Wang and B.Y. Wei, "Experimental and numerical Investigation of convection heat transfer in channels with different types of ribs," Appl. Therm. Eng., vol. 31, pp. 2702- 2708, 2011.

[4] N. Kaewchoothong, K. Maliwan, K. Takeishi and C. Nuntadusit, "Effect of inclined ribs on heat transfer coefficient in stationary square channel," Th. Appl. Mechanics Letters, vol. 7, pp. 344-350, 2017.

[5] S. Kumar and R.S. Amano, "Experimental investigation of heat transfer and flow using V and broken V ribs with in gas turbine blade cooling passage," Heat Mass Transf., vol. 51, pp. 631-647, 2014, doi:10.1007/s00231-014-1436-8.

[6] A. P. Rallabandi, N. Alkhamis and J. C. Han,"Heat transfer and pressure drop measurements for a square channel with 45 deg. round - edged ribs at high Reynolds numbers," J. Turbo Mach., vol. 133, no. 3, 2011, doi: 10.1115/1.4001243.

[7] M. A. Moon, M. J. Park and K.Y. Kim, "Evaluation of heat transfer performances of various rib shapes,” Int. J. Heat Mass Transf., vol. 71, pp. 275- 284, 2014.

[8] T. Hagari, K. Ishida, T. Oda, Y. Douura and Y. Kinoshita,"Heat transfer and pressure losses of W- shaped small ribs at high Reynolds numbers for combustor Liner," J. Eng. Gas Turbine Power, vol. 133, no. 9, 2011, doi:10.1115/1.4002878.

[9] S. Kunstmann, J. Wolfersdorf and U. Ruedel, "Heat transfer and pressure loss in rectangular one side ribbed channels with different aspect ratios," J. Turbo Mach., vol. 135, no. 3, 2013, doi: 10.1115/1.4006871.

[10] P. Singh, Y. Ji and S. V. Ekkad, "Experimental and numerical investigation of heat and fluid flow in a square duct featuring criss-cross rib patterns," Appl. Therm. Eng., vol. 128, pp. 415- 425, 2018.

[11] L. Wang, S. Wang, F. Wen, X. Zhou and Z. Wang, "Effects of continuous wavy ribs on heat transfer and cooling air flow in a square single-pass channel of turbine blade," Int. J. Heat Mass Transf., vol. 121, pp. 514 -533, 2018.

[12] G. Xie, X. Liu, H. Yan and J. Qin, "Turbulent flow characteristics and heat transfer enhancement in a square channel with various crescent ribs on one wall," Int. J. Heat Mass Transf., vol. 115, pp. 283-295, 2017.

[13] Y. Rao, C. Wana and Y. Xu, "An experimental study of pressure loss and heat transfer in the pin fin-dimple channels with various dimple depths," Int. J. Heat Mass Transf., vol. 55, pp. 6723-6733, 2012.

[14] Y. Rao,Y. Feng, B. Li and B. Weigand, "Experimental and numerical study of heat transfer and flow friction in channels with dimples of different shapes," J. Heat Transf., vol. 137, no. 3, 2015, doi: 10.1115/1.4029036.

[15] S. Alfarawi, S. A. Abdel-Moneim and A. Bodalal, "Experimental investigations of heat transfer enhancement from rectangular duct roughened by hybrid ribs," Int. J. Therm. Sci., vol. 118, pp.123-138, 2017.

[16] M. K. Sahu, K. M. Pandey and S. Chatterjee, "Thermo-hydraulic performance of rectangular channel roughened with combined semi-circular and triangular ribs," Heat Mass Transf., vol. 55, pp. 2889 -2900, 2019.

[17] I. Kaur and P. Singh, "Heat and flow characteristics of V-shaped protrusion/concavity combined with miniature V- ribs," Numer. Heat Transf. Part Appl., vol. 78, no. 8, pp. 359-377, 2020, doi:10.1080/10407782.2020.1793549.

[18] P. Singh, J. Pandit and S. V. Ekkad, "Characterization of heat transfer enhancement and frictional losses in a two pass square duct featuring unique combinations of rib turbulators and cylindrical dimples," Int. J. Heat Mass Transf., vol. 106, pp. 629647, 2017.

[19] A. Gupta, M. Kumar and A. K. Patil, "Enhanced heat transfer in plate fin heat sink with dimples and protrusions," Heat Mass Transf., vol. 55, pp. 2247-2260, 2019.

[20] Y. Xie, Z. Shen, D. Zhang and P. Ligrani, "Numerical analysis of flow structure and heat transfer characteristics in dimpled channels with secondary protrusions," J. Heat transf., vol.138, no. 3, 2016, doi: 10.1115/1.4031787.

[21] L. Zheng, Y. Xie, D. Zhang and H. Shi, "Flow and heat transfer characteristics in channels with groove - protrusions and combination effect with ribs," J. Heat Transf., vol. 138, no. 1, 2016, doi: 10.1115/1.4031077.

[22] S. J. Kline and F.A. McClintock, "Describing uncertainties in single-sample experiments," Mech. Eng., vol. 75, pp. 3-8, 1953.

[23] F.W. Dittus and L. M. K. Boelter, "Heat transfer in automobile radiators of the tubular type," Int. Comm. Heat Mass Transf., vol.12, no. 1, pp. 3-22, 1985. 